\title{
PELATIHAN PELAKSANAAN PENELITIAN TINDAKAN KELAS DAN TEKNIK PUBLIKASI JURNAL ILMIAH BAGI GURU SMK NEGERI 1 RENGAT
}

\author{
Pratama Benny Herlandy*, Edi Ismanto, Melly Novalia, Rahmad Alrian \\ Prodi Pendidikan Informatika, Fakultas Keguruan dan Ilmu Pendidikan Universitas \\ Muhammadiyah Riau \\ email: pratamabenny@umri.ac.id
}

\begin{abstract}
The community of public service training that had done has purposed to create educators that are able to conduct the classroom action research. Based on that goal the concrete target which want to be achieved is to build the competence of teachers up to scientific publication by classroom action research. To achieve the goals and targets of the dedication activities being used method through training and mentoring on a regular basis to obtain the competency of the calssrom research action and scientific publication.
\end{abstract}

Keywords: Community of public services, Learning Media, Android Smartphone

\begin{abstract}
Abstrak
Pengabdian pada masyrakat yang dilakukan bertujuan untuk mencipatakan tenaga pendidik yang mampu melaksanakan kegiatan penelitian tindakan kelas. Berdasarkan tujuan tersebut maka target konkrit yang ingin dicapai adalah membangkitkan kompetensi guru untuk dapat melaksanakan publikasi ilmiah melalui penelitian tindakan kelas. Untuk mencapai tujuan dan target dari kegiatan pengabdian maka metode yang dilakukan adalah dengan melalui kegiatan pelatihan dan pendampingan secara berkala sehingga didapatkan kompetensi yang ingin dicapai yaitu mampu melaksanakan penelitian tindakan kelas dan publikasi ilmiah.
\end{abstract}

Kata kunci: Pengabdian, Media Pembelajaran, Smartphone Android

\section{PENDAHULUAN}

Guru merupakan bagain yang penting dalam kerangka pendidikan dasar hingga menengah di Indonesia. Hal tersebut dibuktikan dengan legalitas profesi guru dan doesn pada perguruan tinggi yang diatur dalam bentuk Undang-undang Nomor 14 Tahun 2005 tentang Guru dan Dosen. Kompetensi seorang guru professional yang diatur dalam Undang-undang tersebut meliputi kompetensi sikap, profesionalisme, sosial dan pengetahuan. Seluruh kompetensi tersebut diperlukan karena seoarang guru bertugas tidak hanya mentransfer ilmu pengetahuan namun juga mendidik dan membina karakter peserta didik.
Sebagai perwujudan kompetensi guru yang professional, maka setiap pekerjaan guru seharusnya dilandaskan pada fakta ilmiah. Fakta ilmiah dalam hal ini dibutuhkan agar guru mampu menyajikan materi pembelajaran yang sesuai dengan kebutuhan peserta didik. Fakta ilmiah yang dimaksud dapat berupa analisa tentang tingkat daya serap serta persenase keberhasilan dari suatu materi pembelajaran yang disampaikan dengan metode instruksi khusus tertentu. Untuk mendapatkan data dan fakta terkait hal tersebut maka seorang guru professional perlu melakukan sebuah kegiatan ilmiah dalam bentuk penelitian tindakan kelas.

Penelitian tindakan merupakan penelitian dalam bidang sosial, yang 
menggunakan refleksi diri sebagai metode utama, dilakukan oleh orang yang terlibat di dalamnya, serta bertujuan untuk melakukan perbaikan dalam berbagai aspek. Penelitian tindakan kelas adalah penelitian yang dilakukan oleh guru di dalam kelasnya sendiri melalui refleksi diri, dengan tujuan untuk memperbaiki kinerjanya sebagai guru, sehingga hasil belajar siswa menjadi meningkat.

Penelitian tindakan kelas (PTK) disamping berfungsi sebagai dasar pengembangan dan refleksi pembelajaran oleh guru, saat ini PTK menjadi syarat utama bagi guru dengan status Pegawai Negeri Sipili (PNS) dalam perihal kenaikan pangkat. Perihal tersebut termaktub dalam Peraturan Menteri Pendayagunaan Aparatur Negara dan Reformasi Birokrasi (PermenPANRB) No 16 Tahun 2009 Tanggal 10 November 2009 yang menyatakan bahwa bagi Guru PNS yang akan mengusulkan kenaikan pangkatnya harus memenuhi beberapa kriteria antara lain adalah kredit point yang harus didapat dalam pengembangan diri dan karya tulis. Dari berbagai jenis kelompok karya tulis ilmiah, maka tentunya yang dapat diaplikasikan oleh guru sekaligus dalam kegiatan belajar mengajar adalah penelitian tindakan kelas.

Berdasarkan analisis situasi dan permasalahan yang dihadapi oleh guru, maka diperlukan rancangan solusi untuk mengatasi permasalahan terkait kemampuan guru dalam meneliti dan mempubilkasikan hasil penelitian mereka. Sebagai Instansi yang bersentuhan langsung dengan pengembangan ilmu keguruan, maka FKIP UMRI bertujuan memberikan solusi terkait kemapuan guru dalam melaksanakan penelitian tindakan kelas.

Beberapa solusi yang ditawarkan dalam membantu guru meningkatkan kemampuan mereka dalam meneliti diantaranya dengan melalui kegiatan workshop dan fasilitasi publikasi hasil penelitian yang dilakukan oleh guru. Kegiatan workshop yang diberikan meliputi materi tentang tema penelitian tindakan kelas, pemilihan jenis penelitian tindakan kelas yang sesuai dengan kebutuhan siswa, serta menentukan prosedur penelitian tindakan kelas yang tepat. Dengan diikuti oleh guru yang telah memiliki pengalaman dalam mengajar, diharapkan dapat memberikan contoh PTK yang dengan mudah dilakukan oleh guruguru sesuai dengan target pembelajaran.

Solusi terkait pubilkasi hasil penelitian yang telah dilakukan oleh guru adalah memberikan fasilitas bantuan dalam membuat laporan jurnal hasil penelitian yang sesuai dengan standard jurnal ilmiah. Setelah pelatihan menulis laporan jurnal hasil penelitian, selanjutnya jurnal hasil penelitian akan difasilitasi agar dimuat dalam edisi jurnal yang diterbitkan oleh FKIP UMRI dengan nama jurnal yaitu Jurnal Pendidikan \& Informatika

\section{METODE PENGABDIAN}

Pelaksanaan kegiatan pengabdian dilakukan dengan melalui rangkaian lokakarya dan pelatihan yang dilakukan secara berkala dalam jangka waktu 1 periode pelaksanaan pengabdian. Secara sistematis lokakarya dan pelatihan dilakukan sesuai dengan urutan, sehingga pelaksaan pengabdian dapat mencapai target utama yaitu meningkatkan memapuan guru dalam melaksanakan kegiatan penelitian tindakan kelas (PTK).

Adapun materi yang diberikan dalam pengabdian ini secara simultan diberikan dari pendidikan dasar hingga pendampingan aplikasi dalam perancangan dan publikasi produk. Urutan materi yang mencapai tahapan tersebut adalah sebagai berikut:

1. Lokakarya dasar-dasar penelitian ilmiah.

2. Lokakarya perbedaan PTK dengan penelitian konvensional.

3. Lokakarya pemanfaatan PTK dalam pembelajaran.

4. Pelatihan penyusunan proposal PTK.

5. Pelatihan pengolahan data PTK.

6. Pelatihan penulisan laporan hasil PTK.

7. Pelatihan publikasi karya ilmiah PTK 
Berdasarkan uraian materi tersebut dapat dijelaskan bahwa metode pendekatan yang digunakan secara umum adalah bertujuan untuk memberikan pelatihan dan pendampingan kompetensi guru secara simultan dan bersifat sistematis.

Melalui kegiatan pengabdian ini tentunya peran mitra dalam kegiatan menjadi objek utama dari pelaksanaannya. Mitra yang dalam hal ini adalah kelompok guru dari berbagai bidang studi keahlian yang terdapat di SMK Negeri 1 Rengat. Kelompok guru SMK N 1 Rengat dalam ini merupakan mitra tunggal yang pada pelaksanaan akan distimulus agar dapat mengikuti kegiatan secara aktif dan terampil. Stimulus yang diberikan adalah dengan cara mempersuasi kelompok guru untuk mennerapkan dengan contoh beberapa materi lokakarya dan ikut mengaplikasikan secara langsung materi pelatihan yang diberikan.

Kegiatan pengabdian kepada masyarakat dilakukan pada bulan JanuariFebruari 2018. Adapun rancangan jadwal pelakssanaan kegiatan pengabdian yang akan dilakukan adalah sebagai berikut.

\begin{tabular}{|c|c|c|c|c|c|}
\hline \multirow{2}{*}{ No } & \multirow{2}{*}{ Kegiatan } & \multicolumn{4}{|c|}{$\begin{array}{c}\text { Januari- } \\
\text { Februari } 2018\end{array}$} \\
\hline & & 1 & 2 & 3 & 4 \\
\hline 1 & $\begin{array}{l}\text { Lokakarya dasar-dasar } \\
\text { penelitian ilmiah }\end{array}$ & & & & \\
\hline 2 & $\begin{array}{l}\text { Lokakarya perbedaan PTK } \\
\text { dengan penelitian } \\
\text { konvensional }\end{array}$ & & & & \\
\hline 3 & $\begin{array}{l}\text { Lokakarya pemanfaatan } \\
\text { PTK dalam pembelajaran }\end{array}$ & & & & \\
\hline 4 & $\begin{array}{l}\text { Pelatihan penyusunan } \\
\text { proposal PTK. }\end{array}$ & & & & \\
\hline 5 & $\begin{array}{l}\text { Pelatihan pengolahan data } \\
\text { PTK dan Pelatihan } \\
\text { penulisan laporan hasil } \\
\text { PTK }\end{array}$ & & & & \\
\hline 6 & $\begin{array}{l}\text { Pelatihan publikasi karya } \\
\text { ilmiah PTK }\end{array}$ & & & & \\
\hline
\end{tabular}

Akhir dari pelaksanaan pengabdian adalah mengukur dan menilai capaian dan tingkat keterlaksanaan kegiatan yang telah dilakukan. Pengukuran tersebut dilakukan melalui penilaian terhadap ketercapaian beberapa kriteria. Muara dari pengabdian ini adalah peningkatan kompetensi guru, oleh karena itu pengukuran keberhasilan dari kegiatan pengabdian ini adalah ketika guru telah mampu melaksanakan penelitian dan melakukan publikasi karya ilmiah melalui jurnal cetak maupun online.

Disamping

pengukuran kemampuan guru dalam pelaksanaan PTK ketercapaian target pengabdian juga dilihat dari saat pelaksanaan pengabdian. Pengukuran tersebut dilakukan melalui monev. Monev selanjutnya diisi oleh mitra yang berisi tentang opini dan feedback oleh mitra terhadap pelaksanaan kegiatan pengabdian. Monev dilakukan pada setiap akhir materi dan pada akhir pelatihan

\section{HASIL DAN PEMBAHASAN}

Pengabdian pada masyarakat dengan objek sasaran yaitu guru pada jenjang Sekolah Menegah Kejuruan (SMK) telah dilaksanakan sesuai dengan jadwal yang telah ditentukan. Kegiatan pelatihan pengembangan aplikasi android diikuti oleh 20 orang guru SMK dari berbagai jenis bidang studi. Kegiatan dilakukan dengan menerapkan model seminar dan workshop dengan projek sederhana. Awal kegiatan dibuka secara langsung oleh kepala SMK Negeri 1 Rengat. Seluruh peserta pelatihan dalam kegiatan pengabdian telah menyatakan konfirmasi kehadiran mereka. Rincian peserta yang mengikuti kegiatan pelatihan ini dapat dilihat pada Gambar 1. 
DAFTAR HADIR KEGIATAN PENGABDIAN MASYARAKAT PELATIHAN PENELITIAN TINDAKAN KELAS DAN TEKNIK PUBLIKAS LMLAH BAGI GURU SMK NEGERI 1 RENGAT

\begin{tabular}{|c|c|c|c|}
\hline No & Nama & Jabatan & Tanda \\
\hline 1 & Drs. Adi Mirwan & Kepala Sekolah & \\
\hline 2 & Eva Mulyana, S.Pd & Guru Tetap & Eer \\
\hline 3 & Rizka Kurniati, S.Pd & Guru Tetap & den \\
\hline 4 & Fatmawati,SS & Guru Tetap & found \\
\hline 5 & Herwindo Roxy, M.Kom & Guru Tetap & fonan \\
\hline 6 & Reni Reskina, SE & Guru Tetap & Revem \\
\hline 7 & Lara SuớEmelia, SE & Guru Tetap & druyes \\
\hline 8 & Aswadi, S.Sos & Guru Tetap & $<\infty$ \\
\hline 9 & Andri Febriana, S.Pd & Guru Tetap & Audy \\
\hline 10 & Arief Setiawan & Gurs Tetap & pog \\
\hline 11 & Desmelita, M.Pd & Guru Tetap & \\
\hline 12 & Dra. Murniati, M.Pd & Guru Ietap & preoug \\
\hline 13 & Masikan, S.Pd & Guru Tetap & bill \\
\hline 14 & Ratna Tini, S.Pd & Guru Tetap & 4 \\
\hline 15 & Yuliadi Khatib, S.Pd & Guru Tetap & (1) \\
\hline 16 & Satriyatun, S.Pd & Guru Tetap & +4 \\
\hline 17 & Erma Kunia, S.Pü & Guru Tetap & couneff \\
\hline 18 & Jon Asri, S.Pd & Guru Tetap & amef \\
\hline 19 & M. Yusuf, S.Pd & Guru Tetap & \\
\hline 20 & Nova Yolanda, S.Pd & Guru Tetap & \\
\hline
\end{tabular}

Gambar 1. Daftar Hadir Peserta

Pada kegiatan pengabdian ini, guru dilatih untuk merancang desain penelitian tindakan kelas sesuai dengan standard an prosedur baku dari pelaksanaan Penelitian Tindakan Kelas. Melalui materi workshop, peserta diminta untuk melihat berbagai keadaan kelas dalam proses pembelajaran yang beroptensi menjadi topik penelitian. Selanjutnya peserta dibimbing untuk menuagkan masalah tersebut dalam bentuk latar belakang penelitian tindakan kelas. Disamping Teknik penulisan latar belakang, kegiatan yang dilakukan adalah membimbing peserta dalam menelusuri kajian teori yang berkaitan dengan latar belakang kegaitan PTK yang akan dilakukan. Sebaggai implementasi dari penulisan latar belakang dan kajian teori yang dlikaukan, selanjutnya peserta dibimbing perihal metode pelaksanaan PTK. Dalam pembimbingan tersebut, terdapat beberapa guru yang belum dan bahkan tidak memahami prosedur pelaksanaan PTK.

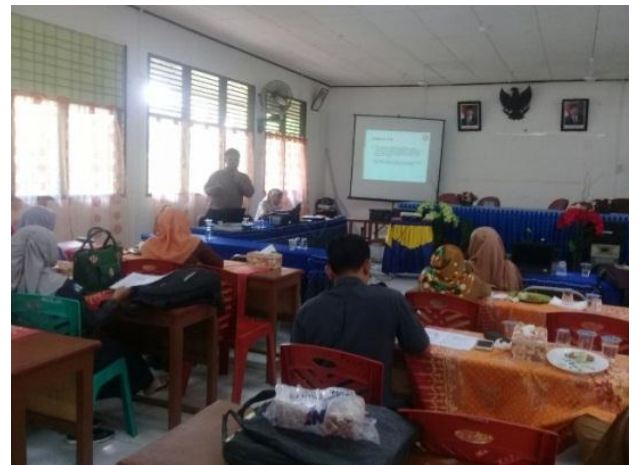

Gambar 2. Pelaksanaan Kegiatan Pengabdian

Untuk mempublikasikan kegiatan PTK yang dilakukan oleh guru, maka peserta juga diberikan materi tentang Teknik publikasi ilmiah. Materi tersebut terdiri atas urgensi publikasi ilmiah dan bagaimana Teknik melakukan pbulikasi melalui jurnal yang terdapat di berbagai instansi, terutama FKIP UMRI. Pada pelatihan ini, para peserta diberikan Teknik, untuk melakukan publikasi agar diterima oleh lembaga penjurnalan. Adapun materi yang disampaikan adalah materi tentang pemilihan judul publikasi ilmiah, pembuatan abstrak serta analisis template jurnal dari berbagai lembaga penjurnalan. Selain itu peserta dibekali dengan materi tentang berbgai lemba jurnal yang terakreditas dan terdapat di Indonesia.

Saat mengikuti kegiatan pengabdian, seluruh peserta sangat antusias dalam melaksanakan berbagai instruksi yang diberikan oleh tim instruktur dari FKIP UMRI. Saat pelatihan berlangsung juga diselingi dengan kegiatan tanya jawab khususnya dalam permasalahan peneidikan, penerapan kurikulum. Berdasarkan hasil pengamatan selama kegiatan berlangsung, para peserta menyatakan tertarik dan sangat merasa perlu dengan kehadiran pelatihan yang telah diberikan karena melalui pelatihan penelitian tindakan kelas para guru mndapatkan pembaruan dalam 
bidang penelitian tindakan kelas dan publikasi ilimah.

\section{KESIMPULAN}

Kegiatan pengabdian kepada masyarakat yang telah dilakukan dapat disimpulkan bahwa:

1. Kegiatan pengabdian berjalan dengan lancar, tepat waktu, dan jumlah peserta sesuai dengan target usulan.

2. Kegiatan pengabdian mendapatkan sambutan yang hangat dari pihak sekolah sebagai objek terselenggaranya kegiatan pengabdian.

3. Seluruh peserta mengikuti kegiatan pengabdian secara konsisten dari awal pertemuan hingga pertemuan terakhir.

4. Melalui kegaitan pengabdian, guru bidang studi di tingkat SMK dapat meningkatkan pengetahuan mereka dalam bidang penelitian tindakan kelas.

Dalam pelaksanaan pengabdian ini tentunya tidak lepas dari kekurangan dalam pelaksanaannya, oleh karena itu terdapat beberapa saran untuk pelaksanaan pengabdian kedepannya. Antara lain adalah sebagai berikut.

1. Kegiatan pengabdian semacam ini sebaiknya dilanjutkan dengan memberikan materi pelatihan yang lebih baik lagi.

2. Guru diberikan pelatihan Teknik publikasi ilimiah melalui jurnal terkareditasi nasional. Dengan harpan, melalui publikasi pada jurnal tnasional terakdreditasi maka akan memberikan peningkatan kulitas publikasi ilmiah guru.

\section{UCAPAN TERIMAKASIH}

Pelaksanaan kegiatan Pengabdian Pada Masyarakat ini tentunya tidak akan terlaksana sesuai rencana jika tanpa bantuan dari berbagai pihak. Oleh karena itu maka penulis mengucapkan terima kasih kepada seluruh pihak yang telah membantu secara materil dan moril sehingga kegiatan pengabdian ini dapat terlaksana dengan baik. Adapun ucapan terima kasih tersebut ditujukan kepada:

1. Rektor UMRI

2. Ketua LPPM UMRI

3. Dekan FKIP UMRI

4. Ketua Program Studi Pendidikan Informatika

5. Kepala SMK Negeri 1 Rengat

6. Majelis Guru SMK Negeri 1 Rengat

\section{DAFTAR PUSTAKA}

1. Adegoke, B., A. (2010). Integrating animations, narratives and textual information for improving physics learning. Electronic Journal of Research in Educational Psychology, 8(2), 725-748.

2. Gonzalez, M.A., Martin, M.E., Liamas, C., et al. (2015). Teaching and learning physics with smartphones. Journal of Cases on Information Technology, 17, 31-50.

3. Laurillard, D. (2007). Pedagogical forms for mobile learning in: Pachler, N. (ed) (2007) Mobile learning: towards a research agenda. London: WLE Centre, IoE.

4. Kitchenham, A. (2011). Models for interdisciplinary mobile learning: delivering information to students. Hersey PA: IGI Global.

5. Kommers, P.M. (2009). Hypermedia learning environment. New York: Routledge.

6. Pachler, N. (ed) (2007) Mobile learning: towards a research agenda. London: WLE Centre, IoE. 